Teknokultura. Revista de Cultura Digital y Movimientos Sociales

ISSNe: $1549-2230$

http://dx.doi.org/10.5209/tekn.64787

\title{
Comida alternativa, comida disputada: el caso de Bristol como enclave de consumo no convencional ${ }^{1}$
}

\author{
Miguel Ángel Sánchez García²; Alfonso Díaz Muñoz ${ }^{3}$
}

Recibido: 20 de junio 2019/ Aceptado: 14 de diciembre 2019 Open peer reviews

Resumen. Dentro de los nuevos patrones y ámbitos de consumo la alimentación alternativa ha experimentado en los últimos años un crecimiento significativo, al calor de otras iniciativas que en la actualidad denuncian la insostenibilidad social y ambiental del sistema económico global, y en particular, del sistema alimentario. Motivadas por este incremento de la demanda, las grandes cadenas de supermercados están accediendo gradualmente a este submercado alimentario, transformando consigo las formas de distribución y comercialización de este tipo de productos. Tomando como caso de estudio la ciudad británica de Bristol, nombrada en 2018 "capital vegana del mundo", y a través de una metodología cualitativa que combina la observación participante en espacios de consumo (supermercados, tiendas y mercado locales) con entrevistas en profundidad a responsables de empresas de distribución y comercialización de comida alternativa, la investigación demuestra que: a) la ciudad de Bristol está configurada por un contexto cultural, económico e institucional que favorece el desarrollo del consumo de comida alternativa, haciendo de ello una marca de ciudad y resaltando la importancia que tiene el territorio en las prácticas de consumo; b) la entrada de grandes cadenas de distribución al mercado de alimentos alternativos está obligando a las empresas que históricamente han controlado este mercado a nuevas estrategias de diferenciación comercial, que modifican la forma en la que se define, regula y vende la comida alternativa; y, c) la visión que la oferta de comida no convencional tiene sobre el consumidor al que se dirige ha transitado en los últimos años desde un consumidor homogéneo a uno más diferenciado, estratégico y ambivalente.

Palabras clave: campo; observación participante; prácticas de consumo; sistema alimentario.

\section{[en] Alternative food, disputed food: the case of Bristol as a non-conventional consumption enclave}

Abstract. Alternative food stands out amongst new consumption modes. It has seen significant growth in recent years along with other initiatives that condemn the social and environmental unsustainability of the global economic system, and particularly, the food system. Motivated by this surge in demand, large supermarket chains are gradually penetrating this food market niche and therefore transforming the ways these products are distributed and commercialised. Taking the British city of Bristol, named 'vegan capital of the world' in 2018, as a case study, and through a qualitative methodology that combines participant observation in consumption spaces (supermarkets and local shops and markets) with in-depth interviews to employees of alternative food distributors and retailers, this research shows that: a) the city of Bristol is configured by a cultural, economic and institutional context that favours the rise of alternative food consumption, making this consumption mode a "city brand" and highlighting the importance of the territory in consumption modes; b) the arrival of large supermarket chains into the alternative food market is forcing companies that historically control this market to develop new commercial differentiation strategies, which is in turn modifying the way alternative food is defined, regulated and commercialised; and c) the perception that non-conventional food retailers hold of their target consumer has shifted in the last years from a homogeneous consumer to a more strategic, ambivalent one.

Keywords: consumer practices; enclave; field; food system, participant observation.

Sumario. 1. Introducción. 2. Metodología y diseño. 3. El caso de la ciudad de Bristol como enclave de consumo no convencional. 4. Ortodoxos y herejes: efectos de la disputa entre viejos y nuevos distribuidores de comida alternativa. 5. Conclusiones: pensar el consumo más allá de los consumidores. 6. Referencias.

Cómo citar: Sánchez García, M. Á.; Díaz Muñoz, A. (2020). Comida alternativa, comida disputada: el caso de Bristol como enclave de consumo no convencional. Teknokultura. Revista de Cultura Digital y Movimientos Sociales, 17(1), 23-33.

\footnotetext{
Este artículo presenta resultados del Proyecto "Gobernanza de la calidad en las cadenas globales agroalimentarias", financiado por el Ministerio de Ciencia e Innovación y Fondos FEDER de la Unión Europea (CSO2017-85507-P).

2 Universidad de Murcia (España)

E-mail: miguelangel.sanchez7@um.es

3 E-mail: alfonso.diaz.munoz@gmail.com
} 


\section{Introducción}

En Europa la alimentación es uno de los ámbitos que mejor refleja los nuevos patrones de consumo alternativo. Una cualidad atribuible, en gran medida, a la herencia histórica de estas prácticas de consumo no convencionales, hoy más generalizadas en todo el continente, pero que vienen a recoger, reinterpretar y actualizar preocupaciones asociadas al proceso de modernización industrial, que emergen en la década de los setenta y ochenta del siglo XX en los países más desarrollados del centro y norte de Europa, articuladas políticamente en torno al movimiento ecologista y al movimiento "verde" (Beck, 2000 y 2006).

Desde la sociología, las miradas hacia este tipo de consumo alimentario han sido diversas, siendo un tema en auge en los últimos años en la sociología española ${ }^{4}$. Una de las principales corrientes que está atendiendo a este fenómeno es la sociología de la alimentación, donde el consumo de comida alternativa se relaciona con los cambios en la estructura social y de valores (Sánchez Vera, 2019). Por otro lado, destacan también las aportaciones desde la propia sociología del consumo, con trabajos que examinan las motivaciones que llevan a los individuos a comprar comida no convencional (Barbeta Viñas, 2015 y 2019; McCarthy y Murphy, 2013; Paddock, 2015). Otro campo relevante es el de la sociología ambiental, que desarrolla un enfoque más centrado en el papel de los consumidores en el contexto de la crisis ecológica (Pardo, 2007), así como el de la sociología de la agricultura y la sociología rural, con estudios que discuten el impacto que los cambios en las demandas de consumo tienen en los procesos de producción de alimentos (Goodman y DuPuis, 2002).

A pesar de sus diferencias, estas propuestas comparten un rasgo común: se aproximan a las nuevas tendencias de consumo alimentario centrándose casi exclusivamente en los consumidores -sus motivaciones, discursos, estilos de vida- prestando menos atención a las nuevas formas de comercialización y distribución de productos alimentarios o a las dinámicas económicas, culturales e institucionales de los territorios donde estas prácticas se hacen posibles $-\mathrm{O}$ imposibles- localmente. Esta sobreestimación del consumidor tiende a ocultar las estrategias de otros actores y espacios fundamentales para entender cómo se configuran y expresan las prácticas de consumo, y más en un contexto como el actual donde las grandes cadenas de distribución han aumentado su control sobre el sistema alimentario, fijando a través de normas y estándares las condiciones de producción y comercialización de los productos alimentarios (Castro,

\footnotetext{
En el caso español, las diferentes modalidades de consumo alternativo se suelen conceptualizar bajo la etiqueta genérica de consumo responsable (Piñeiro, 2011), que engloba y contiene las diferentes adjetivaciones que toma el término de consumo alternativo (ecológico, sostenible, colaborativo, ético, crítico, político, solidario). En este artículo se ha optado por la utilización del concepto 'alternativo/a', dado que goza de un mayor consenso en la literatura especializada a nivel internacional.
}

Moraes y Cutillas, 2017; Reigada, Delgado, Pérez y Soler, 2017). Una gran distribución que, además, se interesa cada vez más por la comida y el consumidor no convencional, tratando de hacerse un hueco en un mercado en auge en el que han tenido históricamente una presencia testimonial (Ferrando, 2017).

En base a lo anterior, este artículo tiene como principal objetivo explorar las relaciones entre el territorio, la comercialización y el consumo de comida alternativa, tomando como caso de estudio la ciudad inglesa de Bristol, catalogada como la "capital vegana del mundo" en 2018 (Wynarczyk, 2019), y que es en la actualidad un terreno empíricamente privilegiado para analizar las prácticas de consumo no convencionales. Para dar cuenta de este objetivo principal, el trabajo se divide en tres objetivos específicos: a) examinar la importancia que tiene el territorio en la promoción y consolidación de prácticas de consumo no convencionales; b) estudiar las estrategias de conservación y diferenciación de los actores que tradicionalmente han monopolizado la distribución y comercialización de comida alternativa ante la penetración de las grandes cadenas de supermercados; y c) indagar en los efectos que la disputa entre la vieja y nueva oferta de comida alternativa genera en las definiciones que se aplican al producto alimentario y al consumidor no convencional.

\section{Metodología y diseño}

La principal propuesta de este trabajo consiste en pensar las nuevas tendencias y culturas de consumo más allá de los consumidores, esto eso: desde un territorio concreto - la ciudad de Bristol- donde éstas se materializan y configuran en un mercado específico en el que participan diferentes actores e instituciones. La estrategia metodológica que se ha seguido para ello ha sido fundamentalmente cualitativa, basada en entrevistas en profundidad y observación participante. Se han realizado siete entrevistas semiestructuradas entre los meses de agosto y diciembre de 2018. Seis han estado dirigidas a responsables de empresas de distribución y comercialización de comida alternativa y una de ellas a una investigadora de la Universidad de Bristol experta en consumo alternativo seleccionada como informante clave (figura 1).

Para el diseño de la muestra, las variables que se han tenido cuenta han sido: tipo de productos distribuidos/comercializados, tipo de empresa, antigüedad en el sector de la comida alternativa y área de actividad, tratando con ello de garantizar la heterogeneidad de la misma. Por su parte, la observación participante se ha realizado en tiendas, supermercados y mercados locales donde se venden productos alimentarios convencionales y no convencionales, con el objetivo de conocer cómo eran presentados los productos alimentarios en los espacios de consumo. Añadir que, para el estudio del entramado socio-institucional de la ciudad y su relación con las prácticas de consumo alternativas, se ha realizado 
un análisis documental mediante la revisión de diversas fuentes (principalmente, artículos de prensa y páginas webs de instituciones, asociaciones y empresas que operan en la ciudad).

Figura 1. Diseño de las entrevistas semiestructuradas. Fuente: elaboración propia.

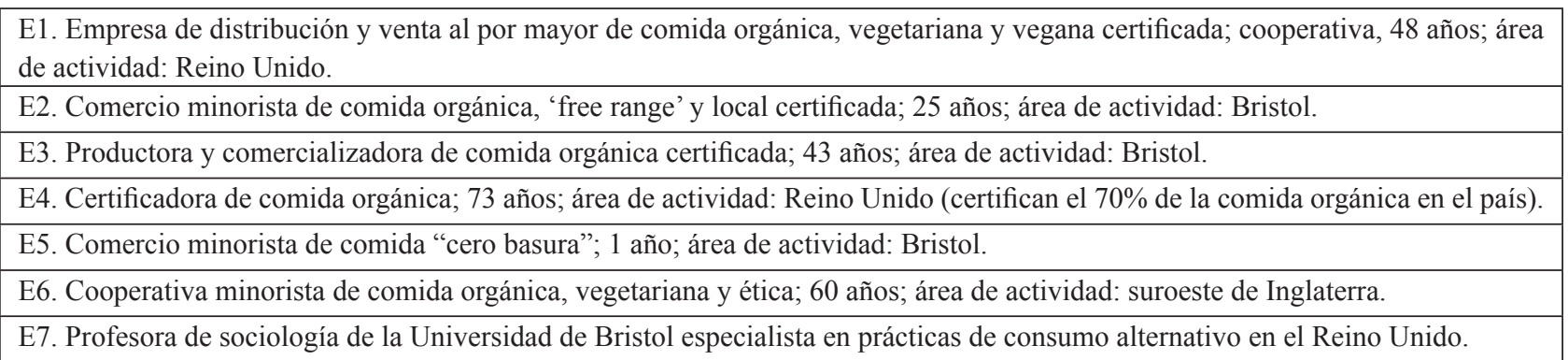

Para el análisis sociológico de las entrevistas, se ha seguido el enfoque sociohermenéutico propuesto por Alonso (2013) para el análisis de los discursos. En este enfoque los discursos no se conciben sólo palabras, sino que funcionan como formas de práctica social que nos remiten a luchas y jerarquías políticas, es decir, a contextos pragmáticos, a nichos (2014, p. 17). Teniendo en cuenta el objetivo de este estudio, el enfoque sociohermenéutico permite indagar en las razones prácticas (Bourdieu, 2008) de los agentes que históricamente han dominado el mercado de la alimentación alternativa, a saber: en el conjunto de relaciones que se producen entre las posiciones que ocupan en dicho espacio y las tomas de posición que realizan a través de estrategias de conservación, defensa y diferenciación como respuesta a la entrada de las grandes cadenas de supermercados.

\section{El caso de la ciudad de Bristol como enclave de consumo no convencional}

La investigación empírica de la que surge este trabajo, realizada en la ciudad de Bristol, obliga a plantear en qué medida las particularidades del territorio influyen en las aparición, legitimación y extensión de prácticas de consumo no convencionales. Esta vinculación entre territorio y consumo permite pensar en la existencia de ciertos enclaves de consumo, en el sentido que otros autores plantean la existencia de enclaves de producción (Pedreño, Castro, Gadea y Moraes, 2015), es decir, territorios con una serie de dinámicas históricas locales y específicas que los convierten en espacios de posibilidad para la aparición y reproducción de procesos socio-económicos específicos. El caso de Bristol como enclave de consumo se centra en dos ámbitos, el sociocultural y el institucional.

\subsection{Contexto sociocultural: el 'Bristol Style'}

En las entrevistas realizadas con responsables de establecimientos de comida alternativa, el "Bristol Style", la idiosincrasia de Bristol, aparece recurrentemente como un factor esencial para entender el florecimiento y consolidación de este tipo de alimentación en la ciudad. Así, las prácticas alimentarias vendrían a completar un estilo de vida no convencional que va más allá de la alimentación y que se manifiesta principalmente a través de un consumo independiente y local, alejado de las grandes empresas multinacionales. Este carácter independiente tiene su origen en la década de los ochenta y noventa, momento en el que la ciudad experimenta una etapa de efervescencia cultural, especialmente en la música y el arte callejero, que otorgan a Bristol un imagen de ciudad contestataria, independiente y creativa (imagen 1$)^{5}$.

Imagen 1. Gloucester Road (Bristol). Fuente: Nathan Evans.

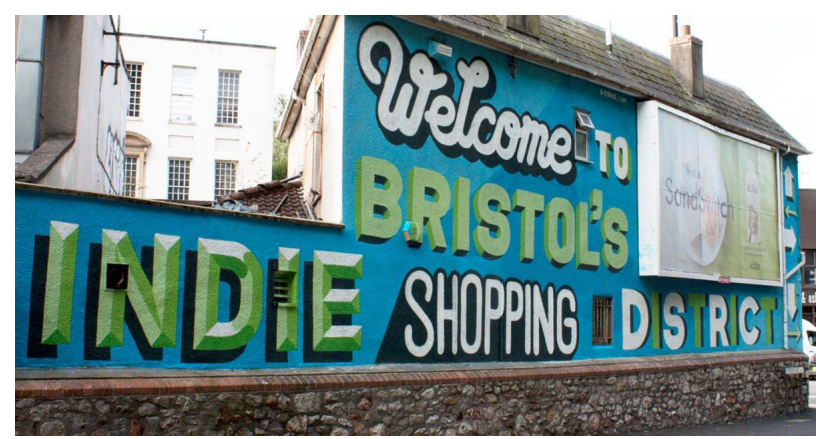

Dentro de la música, el trip-hop, estilo musical que combina el hiphop y la música electrónica, es su corriente más destacada, siendo el grupo más influyente Massive Attack. En el grafiti, sin ningún género de dudas, Banksy, originario de Bristol, es la figura más representativa y reconocida de este movimiento. 
Las transformaciones urbanas recientes que ha experimentado la ciudad han ahondado aún más en este carácter alternativo, resignificando -especialmente a través del grafiti político-y revalorizando los antiguos y céntricos espacios más degradados y penalizados (Wacquant, 2007), que otorgan a la ciudad una marca distintiva muy rentable a nivel turístico. De hecho, en los últimos años, numerosos reportajes de prensa de dentro y fuera del Reino Unido sitúan a Bristol como la ciudad británica más cool, destacando su escena cultural, la calidad de vida y la esencial local del lugar 6 .

En la génesis de Bristol como ciudad no convencional la comida ha jugado un papel central. Uno de los hitos más importantes en este proceso fue la campaña de 2010 en contra de la instalación de un supermercado Tesco - una de las mayores cadenas de supermercados del mundo-, en el barrio céntrico de Stokes Croft, el área urbana que mejor representa este esfuerzo de ciertos grupos sociales -entre los que destacan los colectivos de artistas- por preservar la identidad local, comunitaria y de resistencia frente al mercado. La campaña 'No Tesco', organizada por el consejo vecinal People's Republic of Stokes Croft, incluyó diferentes movilizaciones que en algunos casos fueron respondidas con la presencia de hasta 160 policías antidisturbios. Hoy, Tesco está en Stokes Croft, y la campaña ha mutado del 'No Tesco' al 'Boycott Tesco' [imagen 2 y 3].

Imagen 2 y 3. Manifestación 'No Tesco' y grafiti contra Tesco. Fuente: People's Republic of Stokes Croft.
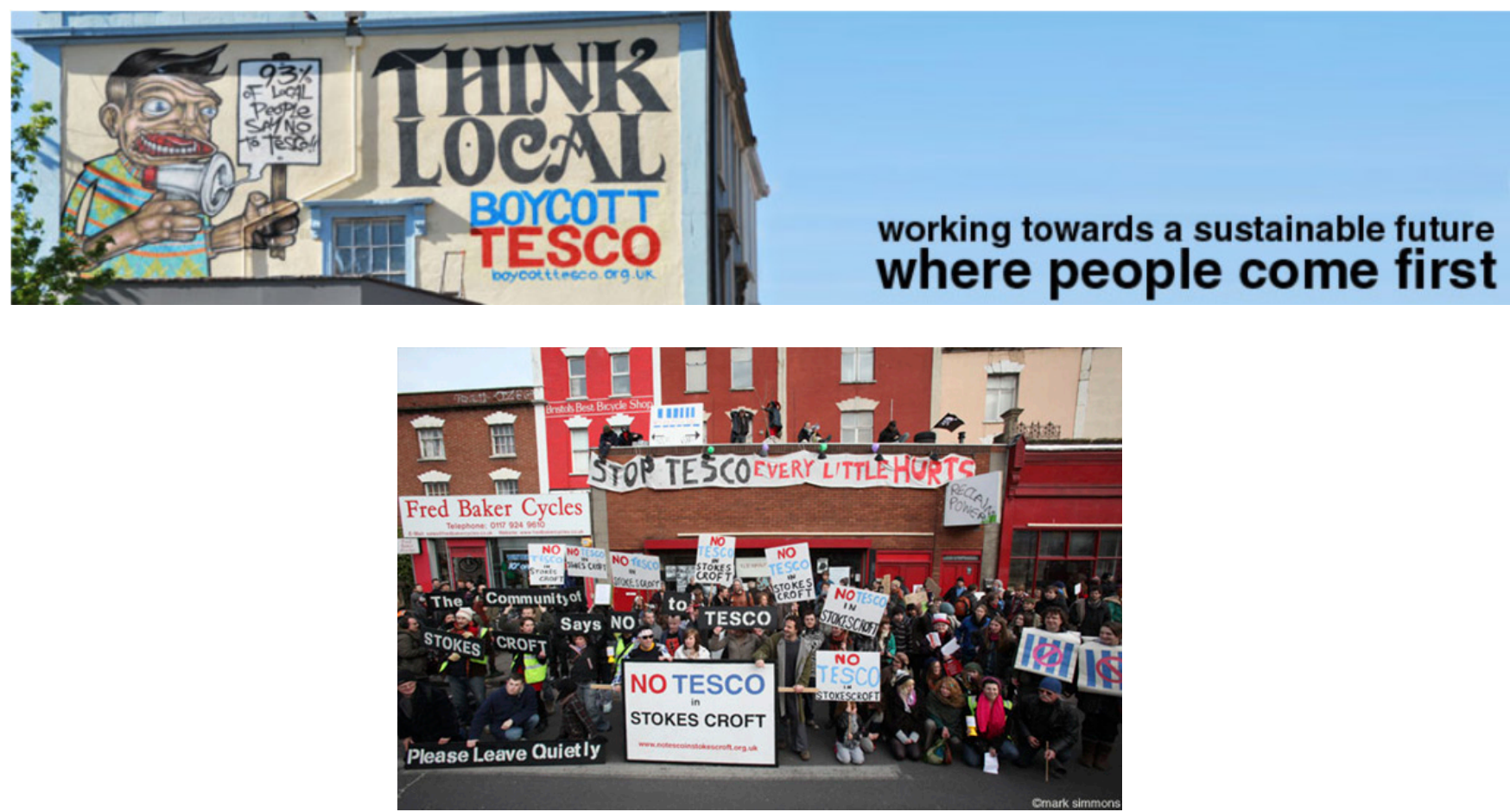

Otro de los indicadores que muestra el papel que juega la alimentación en la construcción de Bristol como ciudad alternativa es el importante número de festivales que se realizan anualmente en torno a la comida. Como, por ejemplo, el 'Valley Fest', festival de música y comida nacido en 2019 en el que toda la comida que se vende es orgánica y se organizan seminarios sobre alimentación. O el 'Bristol Food connections', que celebró en junio de 2019 su quinta edición y tiene como principal objetivo promocionar a los negocios 'locales' e 'independientes' de comida, dándoles la oportunidad, según la organización, de aprender, crear, debatir, explorar, hablar, divertirse y hacer conexiones para conseguir un sistema alimentario que sea mejor para las personas y mejor para Bristol (Bristol Food Connection, 2019, p. 10). Este tipo de eventos, unido a un número importante de estable-

En España, un buen ejemplo es el artículo de El País "Bristol, la ciudad de Banksy". Última consulta: 19.12.2019. cimientos (tiendas, restaurantes, mercados) donde se puede comprar comida catalogada como local, vegetariana, orgánica, ética o vegana, han hecho de Bristol en los últimos años una ciudad reconocida y valorada en Reino Unido como modelo de consumo responsable y sostenible de comida. De hecho, en 2018, un estudio de la plataforma de chefs profesionales Chef's Pencil, catalogó a la ciudad como la "nueva capital vegana del mundo" (Wynarczyk, 2019).

Este carácter independiente, inconformista y comprometido asociado a la ciudad también aparece en los discursos de las distribuidoras y comercializadoras de comida alternativa entrevistadas. La visión que tienen los y las responsables de estas organizaciones es que el habitante de Bristol es un ciudadano concienciado con los problemas sociales, económicos y ambientales que genera el sistema alimentario. Una persona informada y crítica que es capaz de pagar un precio más elevado por un producto que es respetuoso con el medioambiente. Esta norma de con- 
sumo, según los entrevistados, es la que posibilita la existencia y expansión de la oferta de alimentación alternativa en la ciudad, a la vez que consolida una cultura culinaria sana y fuerte:

En Bristol tenemos mucha suerte porque es una ciudad muy independiente y a mucha gente esto le importa, y están dispuestos a pagar más dinero por cosas de más calidad porque saben que la empresa se ha esforzado en hacer algo bueno por el planeta. Bristol es más solidario con sus pequeños comercios y su enfoque ecológico [...]. Nuestro consumidor es, generalmente, más independiente y está mejor informado sobre el medioambiente [E3].

Sin embargo, la entrevista realizada con la investigadora de la Universidad de Bristol, experta en alimentación y consumo, aporta una mirada más matizada, menos idealizada, sobre el consumo y el consumidor de la ciudad. Una visión que subraya las múltiples barreras y desigualdades de carácter económico y espacial que siguen dificultando el acceso de las clases populares a un consumo más saludable, concienciado y sostenible. Y que, además, remarca el carácter distintivo de estas nuevas prácticas de consumo alternativo, que no han perdido su función como marcador social, como vehículo de diferenciación que distingue socialmente a los ciudadanos responsables y comprometidos de los irresponsables e inconscientes:

Se tiene la percepción de que la gente de clase trabajadora no quiere comprar comida sostenible, pero tiene más que ver con los problemas de acceso que tienen a ella, pero el precio, pero también por el lugar donde viven y el tipo de desplazamiento que necesitan hacer, que hace que esta comida sea más cara para esta población. Por ejemplo, algunas tiendas sólo entregan sus paquetes de comida orgánica si tienes un código postal de una zona urbana. Por lo tanto, hay que trabajar para involucrar a las comunidades de clase trabajadora en este consumo, porque creo que las comunidades de clase trabajadora quieren buena comida, pero en este momento es demasiado cara, y sólo es accesible para las clases medias urbanas [E7].

\subsection{Contexto institucional: ciudad alternativa como marca de ciudad}

Junto con los aspectos socioculturales es imprescindible estudiar, por otro lado, el papel que juegan las instituciones públicas en el establecimiento de Bristol como 'meca' de la alimentación alternativa.

En el año 2003, el Ayuntamiento de Bristol se propone hacer de la ciudad una capital 'verde', es decir, una ciudad respetuosa con el medioambiente y con una alta calidad de vida para sus ciudadanos. La primera medida significativa de esta estrategia es de 2007, cuando el mismo ayuntamiento crea la Bristol Green Capital Partnership, una organización cuya misión es actuar como punto de encuentro entre entidades que quieren participar a la hora de Bristol una capital 'verde'. Las primeras entidades en unirse a esta organización fueron el propio Ayuntamiento de Bristol, algunas escuelas públicas locales, la Uni- versity of Bristol y la University of West England, la certificadora de comida más importante de Reino Unido, Soil Association, organizaciones de la sociedad civil, empresas locales y un centro médico local, entre otras. Hoy en día, la Bristol Green Capital Partnership es la asociación más grande del mundo de este tipo, contando con más de 900 miembros (Bristol Green Capital Partnership, 2019). Además de servir como punto de encuentro entre entidades, lleva a cabo una labor de 'lobbying' político, cuyo mayor éxito fue la consecución del premio europeo de 'European Green Capital' para la ciudad de Bristol en el año 2015 (European Commission, 2015). Con la entrega de este premio se reconocía a Bristol su compromiso con respecto a metas ambiciosas de cara a la mejora del medioambiente y el desarrollo sostenible (Bristol Green Capital Partnership, 2019).

Otra iniciativa relevante en este campo es la Bristol Food Policy Council, creada en 2011 y respaldada por distintos actores del sector alimentario en Bristol Esta organización, pionera en el Reino Unido, presentó en 2013 el informe $A$ good food plan for Bristol, donde se expone la visión del sistema alimentario de la ciudad dando importancia a la sostenibilidad medioambiental, la salud de los ciudadanos y el fomento de la economía local. A raíz de este informe, se crea la Bristol Food Network en 2014, que se establece como punto de encuentro para comercios y entidades locales adheridos a la visión del sistema alimentario como un sistema que beneficie la salud de los ciudadanos, es respetuoso con el medioambiente y fomenta la economía local.

Por último, conviene destacar también la labor de las dos universidades ubicadas en la ciudad de Bristol, la University of West England y la University of Bristol, que cuentan con líneas de investigación sobre seguridad alimentaria, las ciudades del futuro y el cambio climático. Y, por otro lado, la organización Sustainable Food Cities, ubicada en Bristol y cuyas entidades coordinadoras son Soil Association, Food Matters y Sustain. Esta organización otorga el premio 'Sustainable Food Cities Award', en sus categorías 'Bronze', 'Silver' y 'Gold' a ciudades del Reino Unido con sistemas alimentarios sostenibles (Sustainable Food Cities, 2019). Bristol ostenta la categoría 'Silver' desde 2016 y actualmente postula a convertirse en 'Gold'.

Como se ha podido observar, el caso de Bristol demuestra la importancia que tienen las dinámicas culturales, sociales e institucionales del territorio en el desarrollo de ciertos patrones de consumo. Entender esta configuración socio-institucional es clave para explicar cómo emerge y se consolida un enclave de consumo que legitima e impulsa una visión particular sobre la alimentación que favorece el consumo alternativo de comida. En el caso de Bristol, la transformación de la ciudad como enclave de consumo alternativo responde, principalmente, a tres procesos: la transformación y resignificación de ciertas áreas urbanas céntricas de la ciudad, convertidas hoy en espacios que se identifican con lo alternativo, lo local y 
lo independiente; la celebración de una serie de eventos anuales de alimentación en los que se promociona y conecta la demanda y oferta de comida alternativa; y una estrategia pública de posicionamiento a través de una marca de ciudad sustentada en el desarrollo sostenible y el consumo responsable.

\section{Ortodoxos y herejes: efectos de la disputa entre los viejos $y$ nuevos distribuidores de comida alternativa}

El aumento en los últimos años del consumo de comida alternativa en el Reino Unido ha convertido a este espacio en un ámbito cada vez más disputado ${ }^{7}$. Nuevos productores, distribuidores, cadenas de supermercados, establecimientos locales, organismos certificadores y consumidores se interesan cada día más por los alimentos alternativos, configurando, junto a actores con una trayectoria más amplia, un entramado complejo y dinámico de relaciones que algunos autores definen como "alternative food relationship" (Kneafsey et al., 2008; Paddock, 2015) $o$, en el caso específico de los productos hortofrutícolas, "alternative agro-food chains" (Sage, 2003).

Precisamente, por el lado de la oferta, la ciudad de Bristol es buen ejemplo de cómo nuevos agentes se interesan cada vez más por el sector de la comida alternativa, percibido como un mercado emergente dentro del sector alimentario. Según el informe de la certificadora de comida orgánica Soil Association (2019), se estima que en el año 2020 la venta de productos orgánicos supere los 2500 millones de libras. Un crecimiento que, como han señalado también otros estudios para el caso español (Alonso, Fernández e Ibáñez, 2014), ha hecho de este espacio un ámbito cada vez más competido y disputado dentro del mercado alimentario, constituyendo en la práctica un campo en el sentido que Pierre Bourdieu le da a este concepto (Bourdieu, 2006).

En términos analíticos, Bourdieu utiliza el concepto de campo para referirse a un sistema específico de relaciones objetivas que, según las posiciones de los distintos actores implicados, pueden ser de alianza o de conflicto, de competencia o de cooperación (Castón, 1996). Así, cada campo tiene sus dominantes y dominados, agentes que permanentemente despliegan estrategias de conservación o usurpación encaminadas a preservar o mejorar su situación dentro del mismo, y de las cuales depende tanto el acceso a las ventajas y bienes que están en juego dentro del campo -económicos, institucionales, simbólicos-, como el establecimiento de criterios más favorables a sus productos o bienes (Bourdieu y Wacquant, 2005).

Aunque no se disponen de datos oficiales sobre los diferentes tipos de consumo alimentario, la información aportada por la certificadora de comida orgánica Soil Association en 2019 sobre la venta de productos orgánicos, constata un crecimiento del $94 \%$ del gasto en productos orgánicos en los últimos 14 años, pasando de 1200 millones de libras en 2004 a los 2400 millones en 2018.
En el caso del mercado de alimentación alternativa en Bristol, se pueden diferenciar dos posiciones principales en conflicto. De un lado, una oferta ortodoxa, compuesta por empresas, cooperativas y tiendas locales de pequeño y mediano tamaño, con una trayectoria dilatada en el mercado de comida alternativa y que exclusivamente comercializan productos no convencionales certificados.

Este tipo de oferta ocupa las posiciones dominadas dentro del mercado alimentario generalista, sin embargo, en el espacio de la alimentación alternativa ocupan posiciones dominantes, gracias al capital simbólico que han ido acumulando y que hace de ellas empresas reconocidas y valoradas por los consumidores expertos. Por otro lado, se situaría una oferta más reciente y más apegada a las lógicas del mercado estándar, formada por grandes cadenas de supermercados que han accedido al campo alternativo de forma gradual, incorporando diferentes líneas de productos orgánicos, veganos o de comercio justo, que se mezclan en sus estantes con productos convencionales. Estas grandes cadenas de distribución británicas, que dominan en la actualidad buena parte del sistema alimentario global, en el mercado alternativo son percibidas con escepticismo por parte de los agentes ortodoxos, que consideran que su entrada en este mercado responde a una estrategia que busca únicamente la rentabilidad económica:

Yo creo, para ser honesto, que es solamente porque la gente se está empezando a despertar, y quieren comprar productos de marcas ecológicas, por una parte, y también quieren comprar productos de marcas que son vistas como... quizás es algo egoísta, pero la gente quiere ser vista como personas concienciadas. Así que, para ser honesto, creo que los tipos dirigiendo las empresas, las grandes empresas, la única razón por la que están cambiando es porque ven que la gente ya no se conforma y quieren cambio, y esto está haciendo que [a los empresarios] les salga rentable hacer estos cambios, no creo que lo hubiesen hecho desde la bondad de sus corazones, no [E3].

\subsection{Cambios en las definiciones y representaciones sobre comida alternativa}

Las relaciones de competencia y disputa dentro del mercado de comida alternativa generan efectos en la manera en la que se define, regula y vende la comida alternativa. Las entrevistas realizadas con responsables de empresas de distribución y comercialización de comida alternativa muestran hasta qué punto la penetración de los supermercados y grandes cadenas de distribución en el campo de la alimentación no convencional está obligando a los agentes ortodoxos a poner en marcha dos estrategias. En primer lugar, una estrategia de diferenciación comercial a través de un mayor uso de redes sociales y páginas web, donde se destaca el impacto social que genera comprar cada producto; un aumento de las interacciones offline y online con 
los consumidores en internet, charlas y jornadas de puertas abiertas; y, por último, una adaptación de la comercialización de los productos a los nuevos tipos de consumo online:

Hemos tenido un pequeño encontronazo con Clipper, que es uno de los grandes distribuidores de té, porque se anunciaron el otro día diciendo que eran la primera empresa del mundo cuyas bolsas de té no tenían plástico, no estaban lavadas con lejía y no estaban genéticamente alteradas... como las nuestras desde hace diez años. Entonces, claro, les hemos mandado un tuit en público diciendo: "Oye, mira, enhorabuena por lo que has hecho, está muy bien que los grandes productores, los grandes actores del mercado de comida y bebida den este paso, felicidades, chapó, pero nosotros esto lo estamos haciendo desde hace diez años. Que tú estás vendiéndolo a bombo y platillo...". Diríamos que en eso estamos intentando cambiar la estrategia, estamos diseñando ahora un nuevo plan de marketing para la empresa. Porque una cosa es no usar eso como un arma de marketing, que lo entiendo $\mathrm{y}$, además, lo respeto y me encanta que sea así, es decir, no ser una empresa muy marketiniana, pero otra cosa es no comunicarlo correctamente [ES1].

La segunda estrategia consiste en establecer los criterios de clasificación que definen y diferencian el consumo responsable, sostenible y comprometido del consumo convencional. Conceptos clásicos de lo alternativo como 'comercio justo' o 'natural' son revisados, reinterpretados y sustituidos por nuevas categorías como 'ético', 'local', 'de proximidad', 'free range', y nuevas prácticas, como no utilizar transporte aéreo a la hora de importar productos, generar 'cero basura' o reducir el plástico. Está lógica de diferenciación y competencia, unida a unas prácticas de consumo cada vez más exigentes, dan lugar a un campo semántico borroso que connota, más que denota, y a varias adjetivaciones y nociones alrededor de lo alternativo.

Por otro lado, los sellos y certificados que utilizan las empresas para garantizar que los alimentos cumplen con determinados requisitos de producción, son especialmente importantes en el mercado de comida alternativa y se han convertido en una de las principales estrategias de usurpación desplegadas por las grandes cadenas de distribución en este campo. Este tipo de etiquetas han devenido en un elemento de disputa entre los viejos y nuevos actores, dando lugar a una multiplicidad de organismos de certificación y sellos, a un mar de símbolos que inundan los espacios de consumo. Un ejemplo de ello, es el sello Fairtrade (comercio justo), que garantiza una serie de valores éticos de los productos. Nacido en 2005, es considerado una de las primeras y más importantes certificaciones y ha sido incorporada en los últimos años por las grandes cadenas de supermercados. Los actores tradicionales de comida alternativa, que lo utilizaron en el pasado y lo siguen utilizando en algunos productos, tienen una visión crítica de este sello y están optando por otro tipo de certificaciones de carácter más local. Una dinámica similar se observa con otro gran sello, el de Soil Association, el mayor organismo certificador de comida orgánica de Reino Unido, y que está siendo incorporado recientemente por las grandes cadenas de supermercados británicos, algo que los actores tradicionales miran con recelo y escepticismo:

Claro, esto es la jugada perfecta para Sainsbury's, Tesco y demás: no tengo que demostrar nada, te pago cincuenta mil pavos y estoy en el círculo de Oro de la Soil Association. Ya no te pones a certificar producto por producto, porque claro, pagas $£ 50,000$, te olvidas y claro, hay mucha gente aquí muy concienciada que va en busca de la certificación en el producto, pero el que viene así despistadillo, como yo he estado muchísimos años... Yo iba a un supermercado y claro, yo veo Soil Association Organic... Sainsbury's está en el círculo de Oro, no en el de bronce, ni en el de plata, en el de oro. Pues venga, a comprarle los productos a Sainsbury's. Lo que nunca hubiera adivinado es que no ha habido ningún proceso de auditoría ni ningún proceso de nada [E6].

Como se ha apuntado anteriormente, en los establecimientos donde se venden los productos alimentarios esta disputa por la diferenciación se traduce, además, en una multiplicidad de etiquetas, mensajes e imágenes que hacen de los productos verdaderos contenedores de mensajes simbólicos. Como señalan Pedreño y Quaranta a partir del trabajo de Ian Cook (1994), la producción simbólica de los alimentos es la forma mediante la cual los agentes adscriben significados a esos productos mediante toda una serie de 'especificaciones', que [hacen] el producto aceptable en cuanto a forma, tamaño, peso, presión interna, color, suministro estacional y precio (Pedreño y Quaranta, 2002, p. 21). En el caso de Bristol, la observación realizada en diferentes espacios de consumo (tiendas, supermercados y mercados locales) muestra cómo esta disputa modifica la producción simbólica de los alimentos, que ya no sólo incorporan referencias a elementos estéticos, sino que también añaden información detallada e imágenes sobre las condiciones de producción de los productos. Así, los supermercados, puestos y tiendas de comida se cuidan y diseñan con minuciosidad tratando de poner en valor la naturalidad, proximidad, singularidad y salubridad del producto, acercando al consumidor al lugar originario del mismo y al momento de la recogida. En este sentido, autores como Ferrando (2017), apuntan que, en el caso de las grandes cadenas de distribución, esta producción simbólica tiene como principal objetivo buscar un tipo de consumidor no convencional para el que recrea escenas parciales de lo que ocurre en los lejanos enclaves productivos, mostrando los aspectos amables y románticos del trabajo agrícola, pero ocultando la otra cara del modelo, la que lo hace posible: la insostenibilidad socio-ambiental de los trabajadores y el territorio (imagen 4). 
Imagen 4. Sección de uva de mesa en el supermercado Asda (Bristol). Empresa anunciada: Moyca (Región de Murcia). Fuente: elaboración propia.

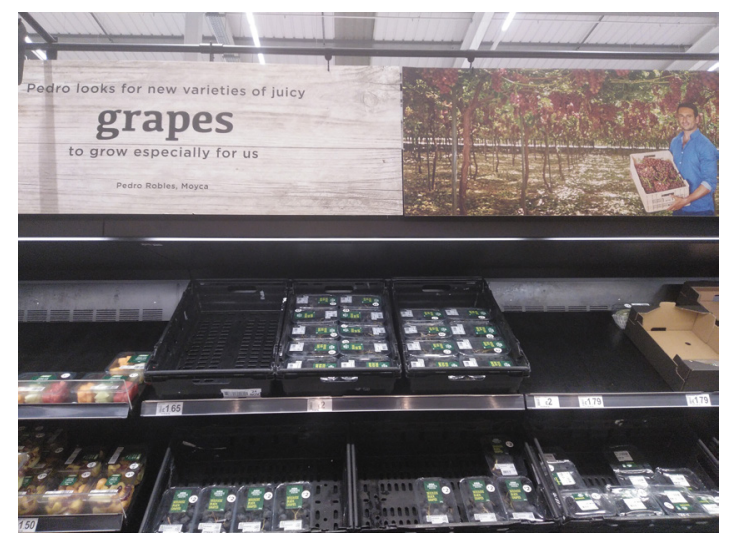

\subsection{Cambios en la visión sobre los consumidores no convencionales}

La lógica de diferenciación y segmentación de la demanda y oferta de comida alternativa no sólo está modificando la forma en la que se define y comercializa la comida, también está cambiando la percepción que tienen los actores de la distribución y venta de comida alternativa de los consumidores a los que se dirigen. Percepción que ha transitado en los últimos años desde un consumidor homogéneo y 'puro' a uno más diferenciado, estratégico y ambivalente, que se mueve motivado por diferentes causas:

[Nuestro cliente] Es clase media concienciada, estamos hablando de gente con cincuenta, sesenta años, y una nueva generación que son universitarios o postuniversitarios, pero muy preocupados en determinados conceptos, es decir, hay gente a la que lo orgánico no le importa nada, pero que no hagan daño a ningún animal, porque tienen una empatía respecto a los animales brutal, están muy civilizados en ese sentido. [...] Y la gente joven también está preocupada por el medioambiente, están preocupados por el problema del plástico, del packaging. Nosotros estamos a marchas forzadas cambiando todo el sistema de packaging, hemos sido pioneros en quitar el plástico de muchos productos [E1].

El análisis de las entrevistas realizadas permite destacar tres perfiles principales de consumidor en este ámbito. En primer lugar, aquellos que se definen como "deep greens", consumidores con gran conciencia medioambiental para los que la comida alternativa no es sino una pieza más dentro de un estilo de vida que se articula alrededor de este aspecto. En segundo lugar, se situaría el consumidor más politizado, que exige disponer de más información sobre el origen de los alimentos y los procesos productivos, demandando una mayor implicación de distribuidores y comercializadores en la mejora de las áreas productoras. Y, por último, aparece un público también por lo general más joven, en busca de tendencias, que realiza prácticas de consumo más inconsistentes articuladas en la mayoría de casos a través de Internet.

Las diferentes miradas sobre el consumidor de comida alternativa que se extraen de las entrevistas confirman que la fragmentación que caracteriza el consumo en la sociedad posfordista, también se han desarrollado y consolidado en el mercado no convencional. En este sentido, conocer las motivaciones, características y perfiles del consumidor no convencional es clave para comprender hacia dónde irán dirigidas en el futuro las nuevas estrategias de distribución y comercialización de comida alternativa, y, por ende, el consumo alternativo. Sin embargo, la mayoría de los trabajos que se interrogan por las razones de los consumidores para comprar un producto $\mathrm{u}$ otro lo hacen estudiando e interrogando a los propios consumidores, sin tener en cuenta la percepción del resto de actores que configuran el consumo alimentario. Con el objetivo de aportar un análisis que complemente los trabajos centrados en la demanda, a continuación, se propone una tipología de consumidores de comida alternativa que toma como referencia a la oferta, es decir, cómo los distribuidores y comercializadores de comida alternativa clasifican y diferencian al consumidor al que se dirigen:

\section{Consumidor aventurero o 'foodie'}

Para este consumidor la comida es un hobby y está en constante búsqueda de nuevos ingredientes con los que preparar nuevos platos, experimentar con distintas maneras de cocinar, etc. Su tendencia hacia el consumo alternativo está motivada por la búsqueda de la autenticidad y la exoticidad. Para este tipo de consumidor, la comida va más allá del sustento y se convierte en un aspecto que adquiere importancia simbólica y cultural (Paddock, 2015).

\section{Consumidor saludable}

Es un consumidor que organiza su dieta buscando mucho más que mantener un peso ideal, y ve la comida como una fuente de salud y bienestar. Consume comida alternativa, y en especial productos orgánicos, porque entiende que estos productos son seguros y sanos, es decir, libres de pesticidas y tóxicos que podrían resultar dañinos para su salud. De ahí que sea un consumidor muy interesado en la procedencia de los alimentos y valore el contacto cercano y directo con los productores.

\section{Consumidor trendy}

Preocupado de seguir las tendencias y estar a la última, su principal motivación es ser visto realizando un consumo alternativo, apropiándose de la distinción que le otorga participar de este tipo consumo. Accede a este consumo no tanto buscando repercusiones positivas para los demás, sino para el mismo, de ahí que se pueda plantear que es el tipo de consumidor que más mira hacia sí mismo de los cuatro perfiles analizados aquí. 


\section{Consumidor concienciado}

Este consumidor está preocupado por el impacto de sus prácticas alimentarias diarias. Ve el consumo como una acción política, una manera de expresarse donde se posiciona a favor de una serie de valores y en contra de otros (Portwood-Stacer, 2012). Al contrario que los otros tres tipos de consumidores, que buscan un retorno a nivel individual -ya sea en forma de mejorar su salud, su experiencia culinaria o la imagen que proyectan de ellos mismos-, el consumidor concienciado parece estar principalmente preocupado por los "otros", en relación con el deterioro del medioambiente y la justicia social. De manera similar al consumidor "sano", este consumidor tiene gran interés por la procedencia de los productos y tiende a favorecer el producto local por dos razones principales: por un lado, al disminuir la distancia que el producto viaja desde el centro de producción al centro de consumo, se reduce su impacto medioambiental en términos de emisiones contaminantes relacionadas con el transporte, y por otra parte, el producto local se ve como beneficioso para la propia comunidad, al retener ésta los beneficios económicos derivados de su producción (Soil Association, 2016).

Conviene, para finalizar este apartado, detenerse en el que parece es el principal factor común que comparten todos los agentes entrevistados sobre el consumidor alternativo: independientemente del subgrupo al que pertenezca, se trata de un individuo informado. Dependiendo del tipo de consumidor, estará más informado sobre unos aspectos u otros, pero parece haber un consenso alrededor de este hecho. La cantidad y calidad de la información en manos del consumidor es percibida por los agentes entrevistados como un requisito necesario para que el consumidor se interese por la alimentación alternativa, lo que explica, en parte, la multiplicación de mensajes, imágenes, etiquetas e información detallada que acompaña a los productos alimentarios en los supermercados y tiendas de alimentación.

\section{A modo de conclusión: pensar el consumo más allá de los consumidores}

Desde hace algunas décadas, el consumo se ha situado en el centro de los debates sobre la insostenibilidad ambiental y social que genera el sistema alimentario global (Alonso et al., 2014; Paddock, 2015). Durante este tiempo, han surgido diferentes conceptos que proponen un cambio en la cultura y los patrones de consumo alimentario, y que se suelen agrupar bajo las nociones de consumo alternativo o consumo responsable (Piñeiro, 2011). Un tipo de consumo que hace referencia a los nuevos espacios de integración en la economía alimentaria definidos, entre otras cosas, por la explosión de orgánico, el comercio justo y local y los alimentos especiales de alta calidad (Goodman y Goodman 2007, p. 2).
En este artículo se se ha realizado una aproximación a este consumo alternativo, pero no desde el análisis de los comportamientos y motivaciones de los consumidores, como suele hacerse desde la sociología del consumo o la alimentación, sino desde dos enfoques diferentes: a) estudiando el territorio y su importancia en el surgimiento, promoción y consolidación de las prácticas de consumo alternativo; y b) observando la oferta de comida alternativa y sus estrategias de distribución y comercialización.

El análisis de la ciudad de Bristol, catalogada en 2018 como "capital vegana del mundo" ha permitido demostrar que la intensidad del consumo alternativo en un territorio no se puede explicar sin atender a las dinámicas históricas locales. Dinámicas que tienen que ver con los imaginarios culturales que se convierten en dominantes y se asocian a determinados lugares, $y$, a su vez, con el esfuerzo de las instituciones públicas por otorgar a las ciudades una marca distintiva que permita diferenciarlas del resto en el mercado turístico. Ambos procesos, en el caso de Bristol, han ido configurando un enclave de consumo que legitima, promueve y facilita el consumo de comida alternativa en la ciudad, aunque persisten barreras de carácter económico, social y espacial que siguen dificultando que este consumo se generalice y se haga extensivo a los sectores populares de la ciudad.

Otro de los ámbitos fundamentales para comprender las características del consumo alternativo es el espacio de la distribución y comercialización de alimentos. Un espacio en el que compiten las empresas tradicionales de comida no convencional y las grandes cadenas de distribución. En la ciudad de Bristol, este espacio está conformado por una oferta ortodoxa, formada por cooperativas y tiendas locales, que exclusivamente comercializa y distribuye comida catalogada de alternativa, ya sea orgánica, ecológica, ética, vegana o 'free range'. No obstante, esta hegemonía se está viendo amenazada en los últimos años por la penetración de las cadenas de distribución comercial.

La entrada al mercado de la comida alternativa de estos grandes supermercados está obligando a los actores tradicionales a modificar sus estrategias comerciales y de comunicación para intentar preservar su posición dominante en este campo. Estas estrategias de conservación y diferenciación están cambiando consigo la forma en la que se define la comida alternativa, así como la manera en la que se regula a través de procesos de certificación, es decir, los criterios por los cuales se valora y evalúa la comida no convencional. Conceptos clásicos como el comercio justo, el vegetarianismo o lo natural son reinterpretados y sustituidos por nuevos conceptos, sellos de certificación y nuevas prácticas que van desde una relación más directa e intensa con el consumidor a la ausencia total del uso del plástico.

Por último, otra de las conclusiones que arroja este trabajo es que la visión que la oferta de comi- 
da no convencional tiene sobre el consumidor al que se dirige ha transitado en los últimos años desde un consumidor homogéneo a uno más diferenciado, estratégico y ambivalente, que se mueve motivado por diferentes causas, que van desde la justicia ambiental al consumo distintivo. No obstante, a pesar de que los distribuidores y vendedores de comida alternativa tienen una percepción del consumidor de comida al- ternativa diferenciada por segmentos y perfiles, comparten una visión común: el consumidor de comida alternativa es un individuo informado. Esta imagen idealizada del consumidor alternativo como consumidor informado, sumada a la competencia entre los actores del mercado por mantener o mejorar sus posiciones en el mercado, convierte a los espacios de consumo en un mar de símbolos y etiquetas.

\section{Referencias}

Alonso, L.E. (2013). La sociohermenéutica como programa de investigación en sociología. Arbor: ciencia, pensamiento y cultura, 189 (761), 1-15.

Alonso, L.E., Fernández, C., e Ibáñez, R. (2014). Crisis y nuevos patrones de consumo: discursos sociales acerca del consumo ecológico en el ámbito de las grandes ciudades españolas. EMPIRIA. Revista de Metodología de Ciencias Sociales, 29, 13-38.

Barbeta, M. (2019). ¿Moda o estilo de vida? El consumo ecológico en la encrucijada. Aposta. Revista de ciencias sociales, $83,30-60$.

Barbeta, M. (2015). Entre renuncias, temores y deberes. Análisis de la estructura motivacional del consumo ecológico. Papers. Revista de sociología, 100(1), 5-33.

Beck, U. (2006). La sociedad del riesgo: Hacia una nueva modernidad. Barcelona: Paidós.

Beck, U. (2000). La democracia y sus enemigos. Barcelona: Paidós.

Bristol Green Capital Partnership (2019). Bristol Green Capital Partnership: Who we are. Recuperado de: https://bristolgreencapital.org/who-we-are/

Bristol Food Connections (2019). Informe final. Recuperado de: https://www.bristolfoodconnections.com/wp-content/ uploads/2019/08/Wrap-Report-.pdf

Bourdieu, P. (2008). El sentido práctico. Madrid: Siglo XXI.

Bourdieu, P. (2006). Las reglas del arte. Génesis y estructura del campo literario. Barcelona: Anagrama.

Bourdieu, P. y Wacquant, L. (2005). Una invitación a la sociología reflexiva. Buenos Aires: Siglo XXI.

Castón, P. (1996). La sociologia de Pierre Bourdieu". REIS. Revista española de investigaciones sociológicas, 76, 75-98.

Castro, C. de, Moraes, N. y Cutillas, I. (2017). Gobernar la producción y el trabajo por medio de estándares. El caso de la industria agroalimentaria en Murcia, Política y Sociedad, 54(1), 111-142.

European Comission (2015). European Green Capital 2015 - Bristol. Recuperado de: https://ec.europa.eu/environment/ europeangreencapital/winning-cities/2015-bristol/

Goodman, D. y DuPuis, M. (2002). Knowing Food and Growing Food. Beyond the Production-Consumption debate in the Sociology of Agriculture. Sociología Ruralis, 42(1), 5-22.

Goodman, D. y M.K. Goodman (2007). Alternative Food Networks. En International Encyclopedia of Human Geography (R. Kitchin y N. Thrift, pp. 208-220). Amsterdam: Elsevier.

Kneafsey, M., Tuomainen, H., Dowler, E., R. Cox, L. Holloway y Venn, L. (2008). Reconnecting consumers, producers, and food: exploring alternatives. Oxford: Berger.

McCarthy, B. y Murphy, L. (2013). Who's buying organic food and why? Political consumerism, demographic characteristics and motivations of consumers in North Qeensland. Tourism \& Management Studies, 9 (1), $72-79$.

Paddock, J. (2015). Invoking Simplicity: 'Alternative' Food and the Reinvention of Distinction. Sociologia Ruralis, 55(1), 22-40.

Pardo, M. (2007). Los desafíos del cambio climático. Temas para el debate, 156, 33-36.

Pedreño, A y Quaranta, G (2002): "Trabajo y sociedad en los campos de la globalización agroalimentaria". En ÁREAS, Revista de Ciencias Sociales, 22, 9-27.

Pedreño, A., Castro, de C., Gadea, M.E. y Moraes, N. (2015). Sustainability, resilience and agency in intensive agricultural enclaves. AGER. Revista de estudios sobre despoblación y desarrollo rural, 18, 139-160.

Peoples Republic of Stokes Croft (2010). Boycott Tesco. Bristol: Peoples Republic of Stokes Croft and Stokes Croft China. Recuperado de: https://prsc.org.uk/the-project-pages/boycott-tesco/

Piñeiro, C. (2011). Comunicación ambiental para la transformación social. Iniciativa del consumo responsable en Madrid. Tesis doctoral, Universidad Autónoma de Madrid.

Portwood-Stacer, L. (2012). Media refusal and conspicuous non-consumption: The performative and political dimensions of Facebook abstention. New Media \& Society, 15(7): 1041-57.

Reig, N. (2018, 15 de agosto). Bristol, la ciudad de Banksy. El País. Recuperado de: https://elviajero.elpais.com/elviajero/2018/06/21/actualidad/1529569601_404616.html

Reigada, A., Delgado, M., Pérez Neira, D., y Soler Montiel, M. (2017). La sostenibilidad social de la agricultura almeriense: una Mirada desde la organización social del trabajo. AGER. Revista de estudios sobre despoblación y desarrollo rural, 7, 1197-222. 
Sage, C. (2003). Social embededness and relations of regard: alternative 'good food' networks in South-West Ireland. Journal of Rural Studies, 19, 47-60.

Sánchez Vera, P. (2019). El homo sanitas: alimentación y tendencias recientes. En Intellectum valde ama. Ama intensamente la inteligencia. Homenaje al Profesor Octavio Uña Juárez (R. Lazcano González, pp. 1731-1746). Madrid: Rafael Lazcano.

Soil Association (2019). Organic Market 2019. Bristol: Soil Association. Recuperado de: https://www.soilassociation. org/media/18224/omr-report-2019-interactive.pdf

Soil Association (2016). The UK organic consumer. Bristol: Soil Association.

Sustainable Food Cities (2019). Current Sustainable Food Cities Award Winners. Recuperado de: http://sustainablefoodcities.org/awards/awardwinners.html

Ferrando, T. (2017). Corporate Governance through Certification Schemes and Eco-Labeling: The Value of Silence. En The Corporation: A Critical, Interdisciplinary Handbook (G. Baars and A. Spicer, pp. 372-382). Cambridge: Cambridge University Press.

Wacquant, L. (2007). La estigmatización territorial en la edad de la marginalizad avanzada. Ciências Sociais Unisinos, 43(3), 193-199.

Wynarczyk, N. (2019, 18 de febrero). Bristol is vegan capital of the world, a new study claims. Independent. Recuperado de: https://www.independent.co.uk/life-style/bristol-vegan-capital-world-chefs-pencil-online-searches-uk-australia-a8732796.html 